\title{
Implementasi Customer Relationship Management pada Sistem Informasi Pemasaran Toko Wibowo Motor
}

\author{
Ervyna Yulianingsih ${ }^{1)}$, Hani Atun Mumtahana ${ }^{2)}$, Ridho Pamungkas ${ }^{3)}$ \\ Sistem Informasi, Universitas PGRI Madiun, Jl. Setia Budi NO.85, Kanigoro, Kec, Kartoharjo, Kota Madiun, \\ Jawa Timur 63118 \\ E-mail:vynamasif@gmail.com ${ }^{1)}$, hanimumtahana@unipma.ac.id ${ }^{2)}$, ridho.pamungkas@unipma.ac.id ${ }^{3)}$
}

\begin{abstract}
Wibowo Motor Shop is a trading unit engaged in the automotive sector, namely the sale of motorcycle spare parts and motorcycle accessories. The Wibowo Motor store in doing its marketing has not utilized information technology in order to increase customers. Toko Wibowo Motor wants to maintain good relations with customers by implementing a website-based Customer Relationship Management method. Customer Relationship Management is a strategy that is combined with the use of information technology in the form of software and computer hardware to assist companies in managing customer relationships. This marketing information system was built using the waterfall method. The result of the implementation of the marketing information system is that it can manage customer data, product data, promotions, product sales.
\end{abstract}

Keywords - : marketing information system, customer relationship management, waterfall

\section{PENDAhULUAN}

Teknologi informasi dan komunikasi sangat membantu manusia sebagai individu ataupun manusia sebagai bagian dari suatu organisasi untuk pengolahan data dengan lebih cepat dan tepat,.Sehingga dapat memperoleh suatu informasi yang tepat sasaran bagi yang membutuhkan informasi tersebut. Kemampuan komputer yang dikembangkan lebih lanjut sebagai penyiapan informasi, dapat membangun efektifitas penyelesaian pekerjaan. Volume informasi yang sangat besar, jenis perkiraan yang diulang, kecepatan waktu dan ketepatan untuk membuat laporan yang diharapkan dapat membantu kegiatan kantor atau organisasi, saat ini bukan masalah besar. Semuanya harus mungkin terkomputerisasi..(Purnomo, 2020) Persaingan di dunia bisnis saat ini semakin luar biasa, sehingga para pelaku bisnis perlu melakukan strategi penting untuk memasarkan produk mereka. Selain itu, prestasi pengusaha bisnis tidak hanya terletak pada kualitas barang atau jasa, tetapi juga seberapa jauh usaha pengusaha dalam memberikan layanan terbaik. Peningkatan kualitas layanan .dan produk UMKM dapat menimbulkan efek positif dan berdampak penting terhadap loyalitas pelanggan. Maka pada saat itu hal ini sangatlah penting bagi pelaku usaha untuk terus meningkatkan kualitas agar nantinya timbul kepercayaan dari pelanggan.Pelanggan pengguna e-commerce pada bulan Januari 2020 tercatat sebesar $24 \%$ dan naik menjadi $66 \%$ saat ini. Hal ini tentunya menjadi keharusan bagi pelaku usaha agar lebih meningkatkan kualitas pelayanan mereka sehingga pelanggan.percaya (Masturi et al., 2021). Dalam Perkembangan perindustrian peran teknologi serta informasi dalam bisnis menjadikan pelaksanaan strategis menjadi penentuan berhasilnya perusahaan. Bidang manajemen, kekuatan strategis berpengaruh terhadap persaingan global dalam perusahaan domestik. Sektor bisnis merupakan sektor otomotif, bilamana Indonesia ialah

Salah satu perkembangan otomotif terbesar kedua di ASEAN setelah Thailand (Supandi et al., 2018). Toko Wibowo Motor merupakan Unit Dagang yang bergerak dibidang otomotif yaitu penjualan sparepart motor dan aksesoris variasi motor. Lokasi toko wibowo motor berada di desa Bangunsari, Kecamatan Mejayan, Kabupaten Madiun. Penjualan sparepart motor semakin meningkat, sehingga banyak bengkel yang menjual sparepart motor, masih banyak toko atau bengkel yang menjual sparepart motor yang belum menerapkan pelayanan optimal terhadap pelanggan. Dengan adanya strategi pemasaran yang masih konvensional, berpeluang dalam mendapatkan calon konsumen, hal ini sangat disayangkan mengingat produk sparepart motor banyak dicari. Pengedaran informasi yang kurang akurat menyebabkan pelanggan kurang memahami mengenai informasi tentang produk sehingga dapat mempengaruhi pelanggan untuk beralih ke kompetitor lain. Dengan adanya kendala yang dihadapi oleh Toko Wibowo Motor, maka dibutuhkan sistem informasi pemasaran berbasis website dengan menggunakan Customer Relationship Management (CRM) dengan menampilkan landing pages pada menu beranda dan menambahkan fitur kritik dan saran pelayanan kepada pelanggan dan fitur pesan untuk menghubungi pihak toko. Diharapkan dengan adanya sistem informasi pemasaran akan 
Website : http://pilar.unmermadiun.ac.id/index.php/pilarteknologi

membantu kendala yang ada di Toko Wibowo Motor, selain itu dengan adanya sistem tersebut dapat dipergunakan sebagai sarana promosi agar mempermudah promosi Toko tersebut.

\section{METODE PENELITIAN}

Penerapan strategi CRM ini menggunakan sistem informasi pemasaran berbasis web. Manajemen layanan pelanggan digunakan untuk menyimpan permintaan pelanggan untuk membuat hubungan yang baik dengan pelanggan. Penerapan strategi CRM pada sistem informasi pemasaran bertujuan untuk mempertahankan pelanggan yang ada dengan cara menambah kepuasan pelanggan terhadap pelayanan yang diberikan. (Amatullah et al., 2018) Peneliti menggunakan metode waterfall dalam mengembangkan sistem informasi pemasaran yang akan dibangun. Berikut ini merupakan rancangan penelitian yang telah dibuat :

1. Analisa kebutuhan perangkat lunak

Peneliti mengumpulkan kebutuhan perangkat lunak secara intensif . agar dapat dipahami oleh pengguna.

2. Desain sistem

Peneliti melakukan desain sistem dengan pembuatan program perangkat lunak termasuk struktur data, arsitektur perangkat lunak, representasi antar muka dan prosedur pengkodean sistem .

3. Pembuatan kode program

Setelah peneliti mendesain sistem maka peneliti harus melakukan pemindahan ke dalam program perangkat lunak agar program sesuai dengan desain yang telah dibuat pada tahap desain.

4. Pengujian

Pada tahap pengujian peneliti menentukan bahwa semua menu sudah di uji untuk menimalisir error dan keluaran harus sesuai dengan yang diharapkan.

5. Pemeliharaan (maintenance)

Setelah selesai dalam pembuatan sistem, peneliti melakukan analisis dan desain yang akan digunakan oleh pengguna. Kemudian sistem yang telah dibuat harus dilakukan pemeliharaan.

\section{A. Perancangan Sistem}

\section{HASIL DAN PEMBAHASAN}

Pada penelitian ini menggunakan bahasa pemodelan UML untuk desain perancangan sistem. Model yang digunakan yaitu Use case diagram, Class Diagaram, Acitivy Diagram.

a) Use case Diagram

Use case diagram digunakan untuk mengetahui fungsi apa saja yang ada di dalam sebuah sistem informasi dan siapa saja yang berhak menggunakan fungsi fungsi itu.(Hanafri et al., 2019) Use case diagram ini menggambarkan 2 (dua) aktor dengan sistem yaitu admin dan pelanggan. Berikut ini merupakan use case admin dan pelanggan :

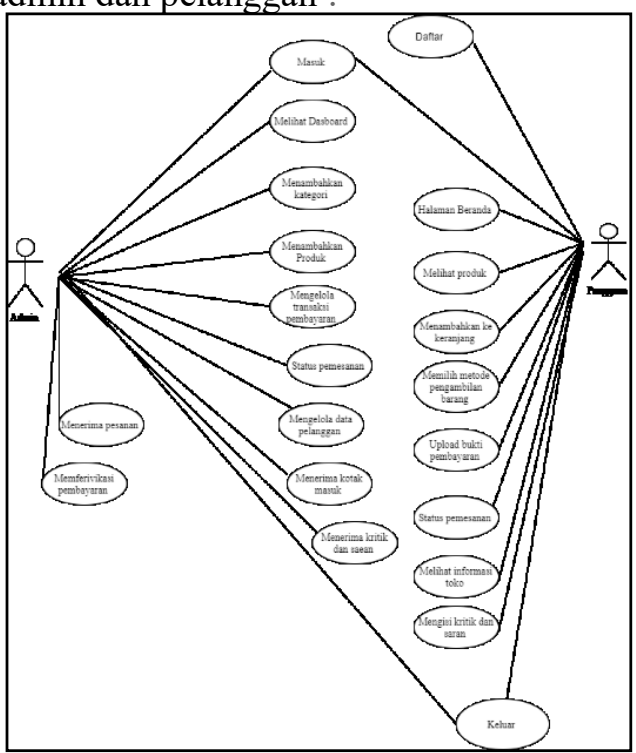

Gambar 1. Use case diagram admin dan pelanggan 
Website : $\underline{\text { http://pilar.unmermadiun.ac.id/index.php/pilarteknologi }}$

b)

Class Diagram

Class Diagram merupakan diagram yang menggambarkan hubungan apa saja yang terjadi antara suatu objek dengan objek lainnya sehingga terbentuklah suatu sistem.(Fitri Ayu and Nia Permatasari, 2018)

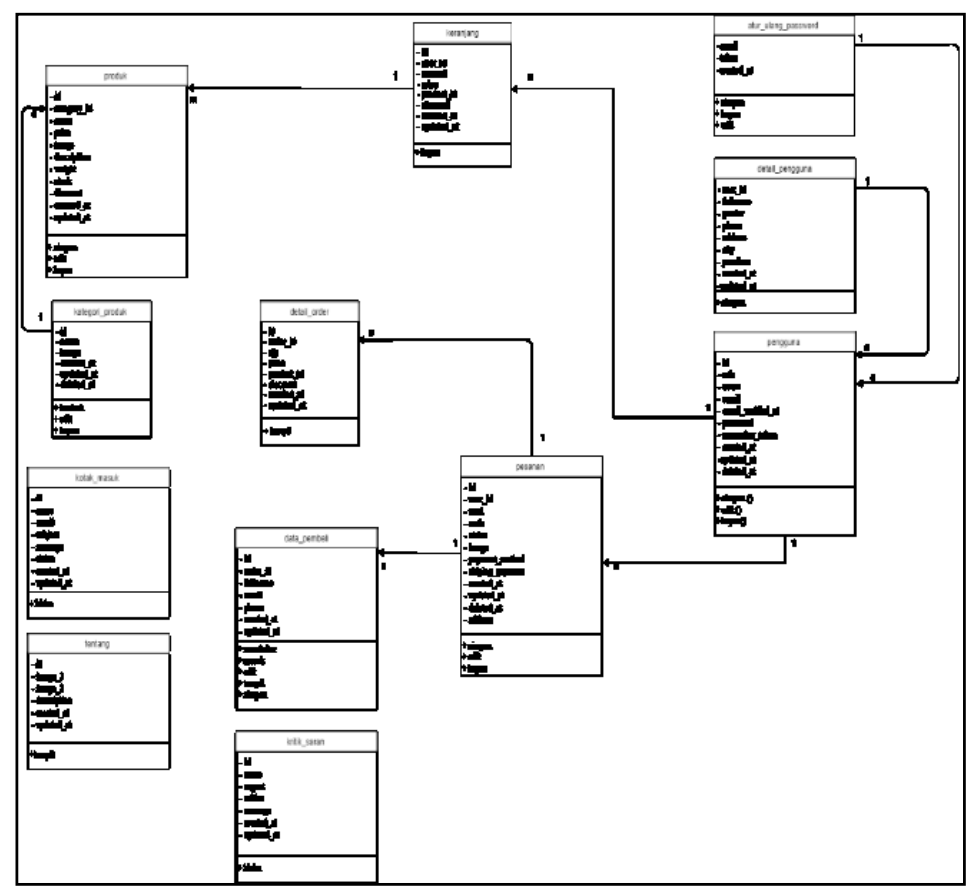

Gambar 2. Class Diagram Sistem informasi pemasaran

Class diagram pada sistem informasi pemasaran ini memiliki 14 tabel yaitu diantaranya Tabel data_pembeli, tabel detail_order, tabel detail_produk, kategori_produk, keranjang, tabel kotak_masuk, tabel kritik_saran, tabel password, tabel pembayaran, tabel pendaftaran_pengguna, tabel pengguna, tabel pesanan, tabel produk, tabel tentang.

c) Activity Diagram

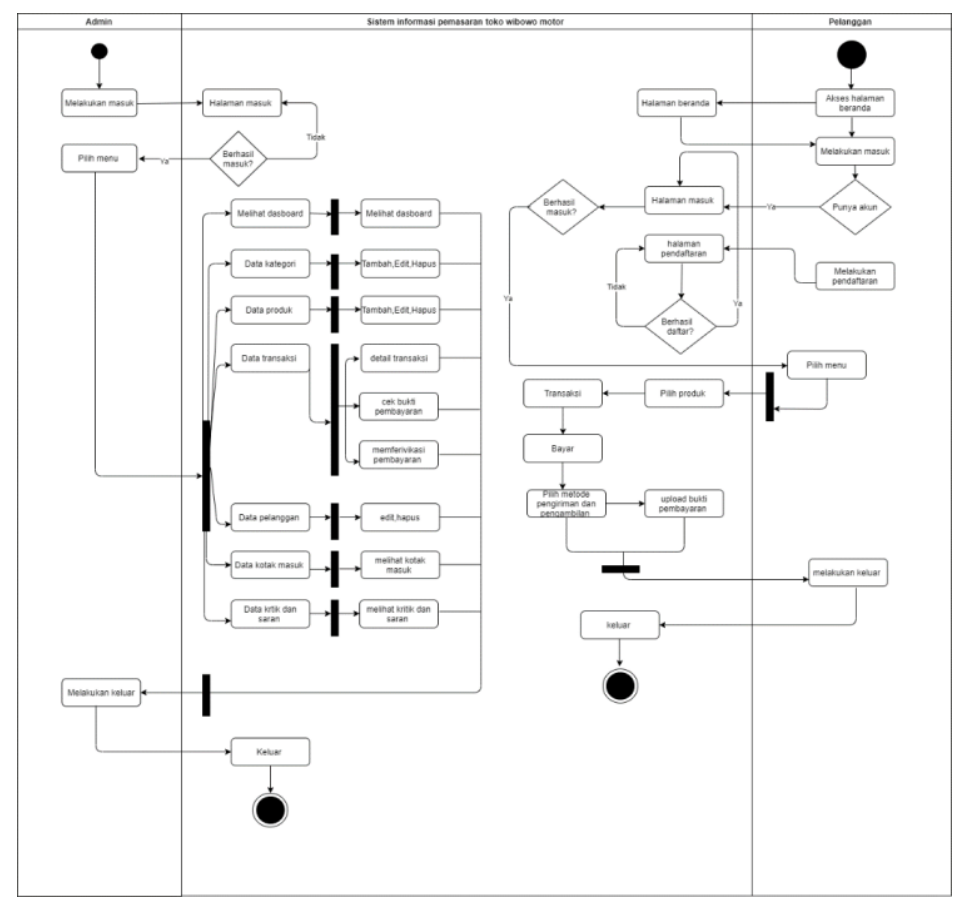

Gambar 3. Activity Diagram admin dan pelanggan 
Website : http://pilar.unmermadiun.ac.id/index.php/pilarteknologi

Activity diagram diatas menggambarkan admin dan pelanggan tersebut dapat menggambarkan bahwa admin dan pelanggan dapat melakukan keluar serta dapat melakukan sebagai berikut :

1) Melihat dashboard

2) Menambahkan, edit dan hapus data kategori

3) Menambahkan, edit dan hapus data produk

4) Mengelola data transaksi yaitu memferivikasi pembayaran, detail transaksi, dan mengecek bukti pembayaran

5) Mengedit dan menghapus data pelanggan

6) Melihat kotak masuk

7) Melihat kritik dan saran berikut :

Sedangkan pelanggan dapat melakukan masuk dan keluar serta dapat melakukan sebagai

1) Mengakses halaman beranda

2) Melakukan pemesanan di keranjang

3) Memilih metode pengambilan yaitu ambil ditempat atau melaui jasa pengiriman

4) Mengirim bukti pembayaran

5) Mengisi kritik dan saran.

B. Implementasi Customer Relationship Management (CRM)

Customer Relationship Management ialah strategi serta metodologi yang disatukan dengan pemanfaatan teknologi informasi perangkat lunak komputer dan perangkat keras komputer dalam membantu perusahaan mengelola pelanggan dan menjaga hubungan baik dengan pelanggan (Putu, 2019). Implementasi Customer Relationship Management pada sistem informasi pemasaran adalah sebagai berikut :

1) Tampilan berupa deskripsi produk, harga produk, gambar produk.

2) Menu toko yang ada pada webstite menampilkan semua produk yang ada pada toko Wibowo Motor.

3) Menu kritik dan saran dari pelanggan kepada pihak toko mengenai dengan pelayanan dan produk.

4) Menu untuk mengirim pesan dari pelanggan kepada pihak toko mengenai produk.

5) Fitur tambahkan keranjang jika ingin melakukan transaksi pembayaran.

6) Halaman landing pages pada beranda berupa informasi diskon yang diadakan oleh toko wibowo motor.

7) Fitur pemilihan pengiriman produk yaitu ambil ditoko atau menggunakan jasa pengiriman.

C. Impelementasi Sistem

1) Tampilan landing pages pada beranda

Pada tempilan ini merupakan strategi dalam penerapan customer relationship management guna untuk menarik pelanggan.

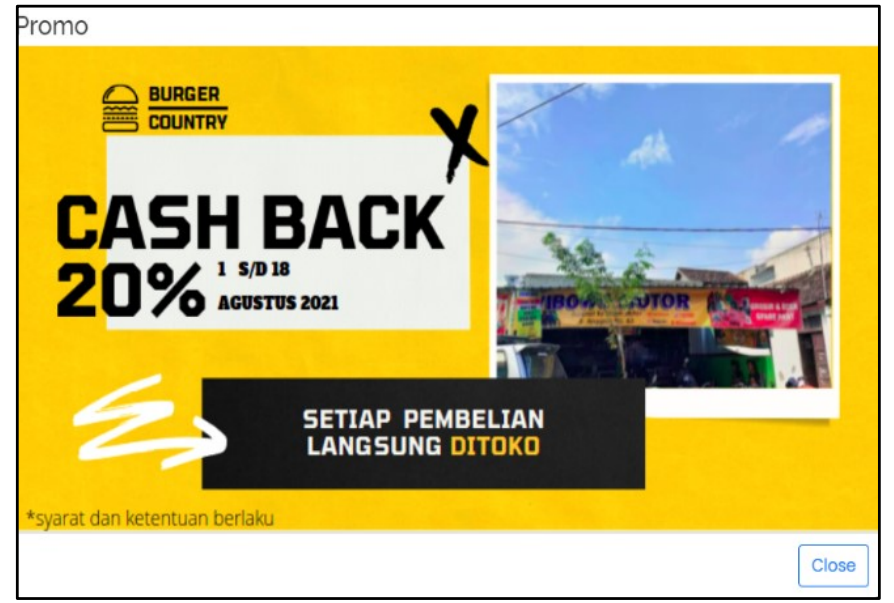

Gambar 4. Implementasi landing pages pada beranda 
Website : $\underline{\text { http://pilar.unmermadiun.ac.id/index.php/pilarteknologi }}$

2) Tampilan halaman beranda

Pada halaman ini merupakan tampilan beranda yang memberikan informasi tentang diskon produk.

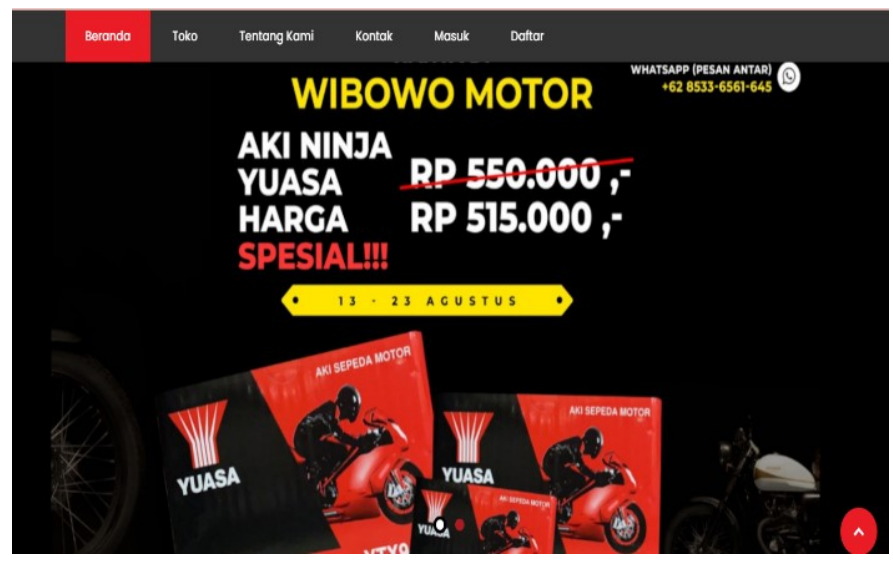

Gambar 6. Halaman beranda pada sistem informasi pemasaran

3) Tampilan halaman login

Pada halaman login merupakan tampilan admin atau pelanggan jika ingin masuk kedalam sistem. Dan jika pelanggan belum mempunyai akun pelanggan harus daftar akun terlebih dahulu.

4) Tampilan Menu toko

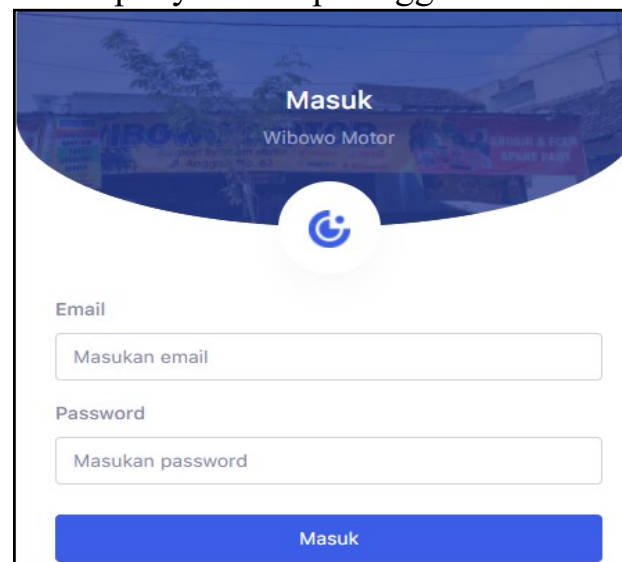

Belum punya akun? Daftar

Tidak bisa masuk? lupa password

Gambar 7. Halaman login pada admin dan pelanggan

Pada halaman menu toko merupakan halaman berisi tentang semua produk yang ada pada toko wibowo motor.

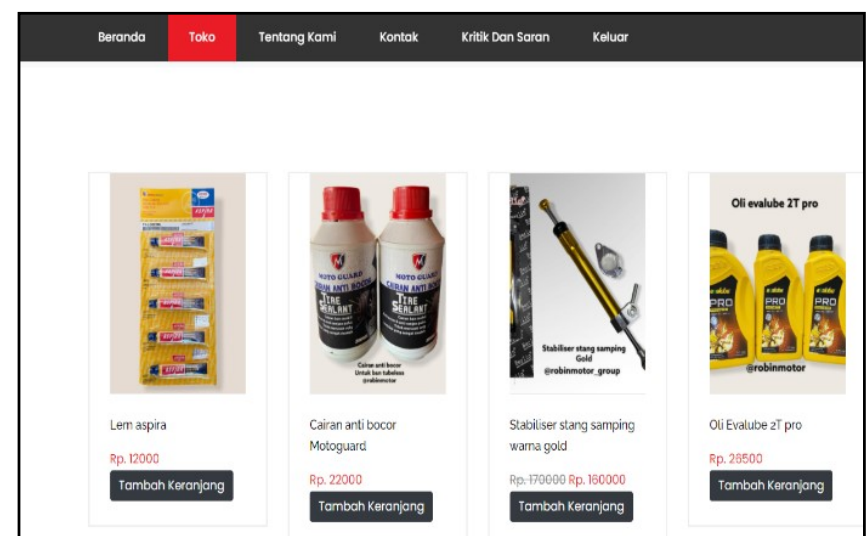

Gambar 8. Halaman menu toko 
Website : $\underline{\text { http://pilar.unmermadiun.ac.id/index.php/pilarteknologi }}$

5) Tampilan detail produk

Pada halaman detail produk berisi tentang nama produk, harga produk, deskripsi produk, stok produk, dan jumlah yang akan dibeli oleh pelanggan.

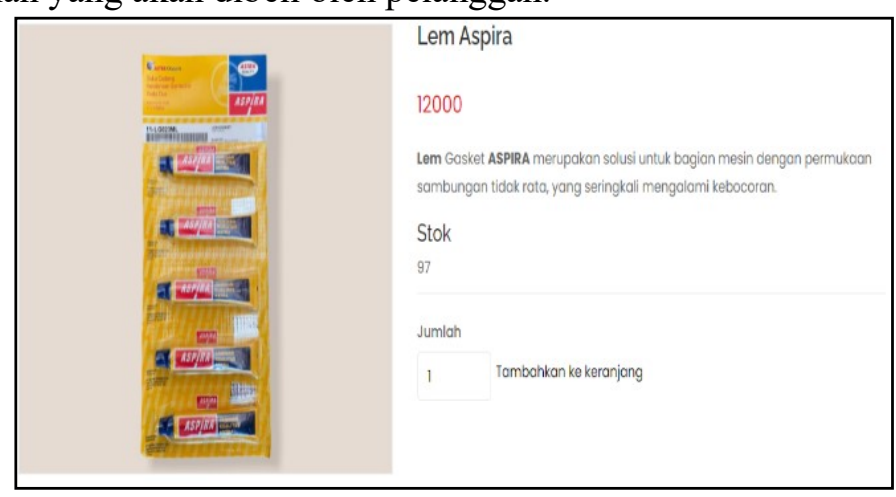

Gambar 9. Halaman detail produk

6) Tampilan keranjang belanja

Pada halaman ini merupakan tampilan keranjang belanja jika pelanggan ingin membeli produk.

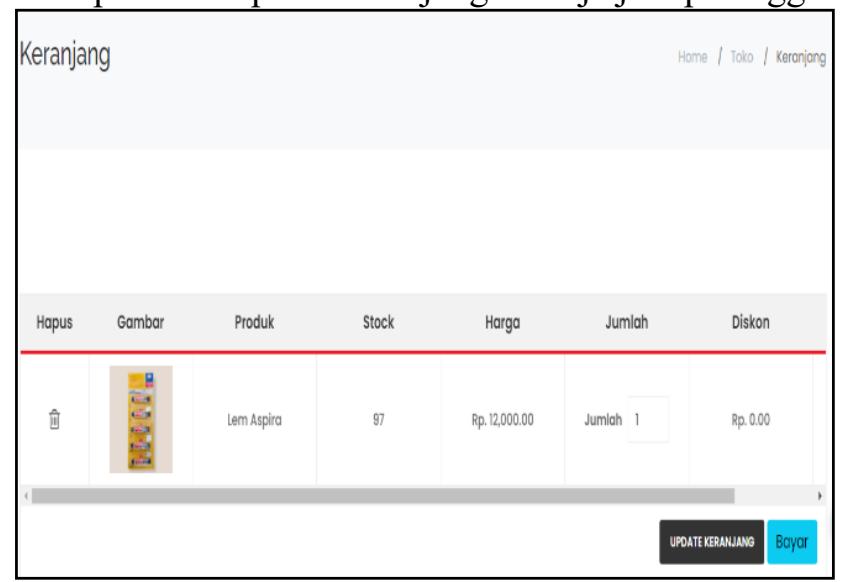

Gambar 10. Halaman keranjang belanja

7) Tampilan checkout pembayaran

Pada halaman ini pelanggan harus mengisikan alamat lengkap kemudian klik cek ongkir pada jasa pengiriman, pelanggan dapat memilih jasa pengiriman melalui JNE, TIKI, dan kantor pos.

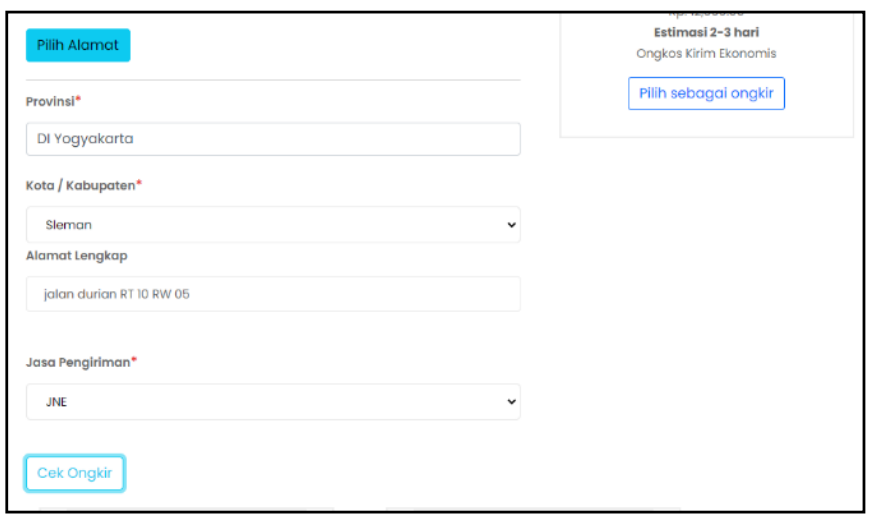

Gambar 11. Halaman checkout pembayaran

8) Tampilan upload bukti pembayaran

Pada halaman upload bukti pembayaran pelanggan dapat melihat detail barang yang akan dibeli kemudian transfer pada rekening pemilik toko kemudian upload bukti transfer. 
Website : $\underline{\text { http://pilar.unmermadiun.ac.id/index.php/pilarteknologi }}$

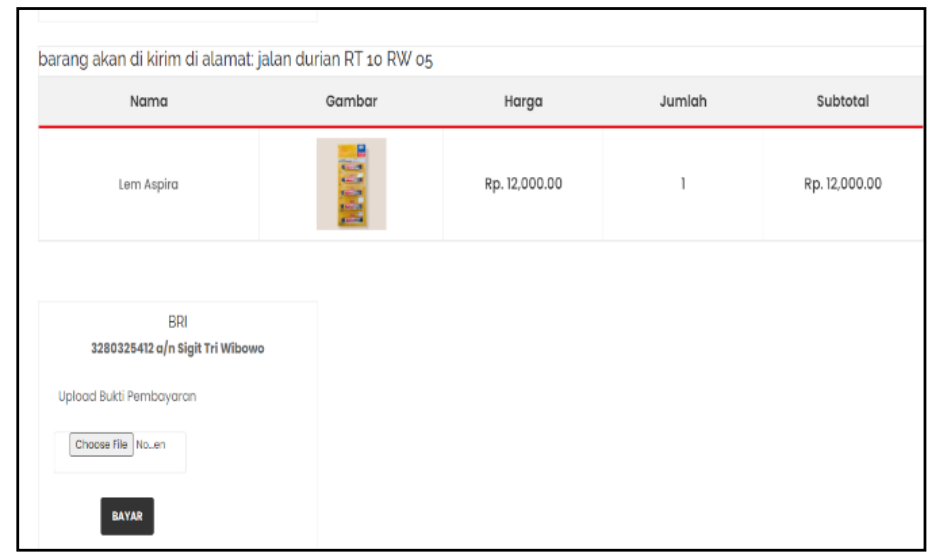

Gambar 12. Halaman upload bukti pembayaran

9) Tampilan kritik dan saran

Pada halaman ini merupakan penerapan customer relationship management kepada pelanggan agar dapat memberikan kritik dan saran mengenai produk.

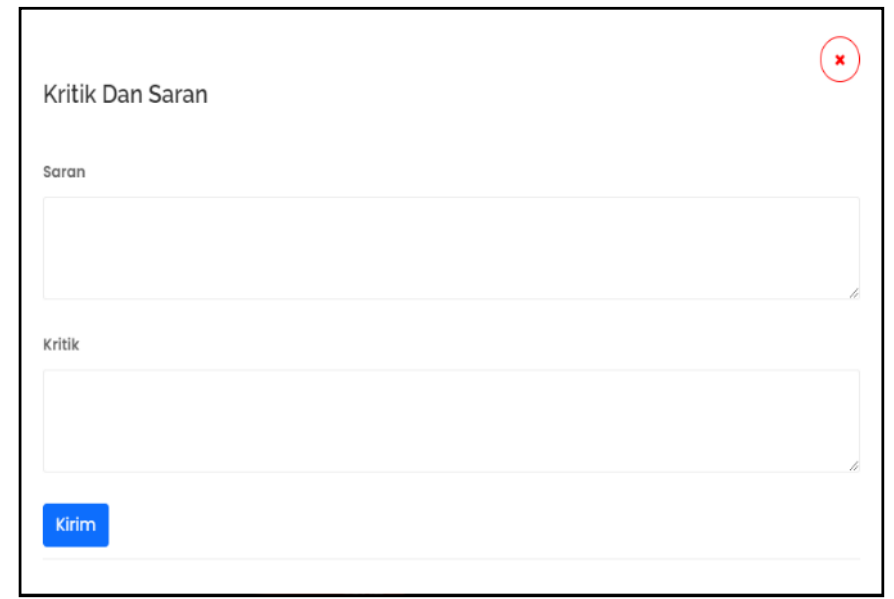

Gambar 13. Halaman kritik dan saran

10) Tampilan kontak

Pada halaman kontak ini berisikan alamat toko dan nomor WhatsApp toko jika pelanggan ingin mengirimkan pesan melalui wa dan pelanggan dapat mengirimkan pesan mengenai produk dari website tersebut.

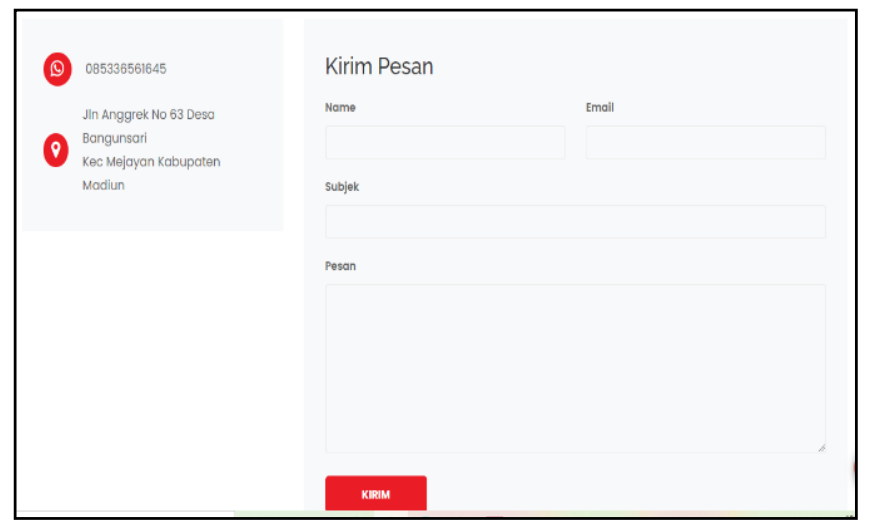

Gambar 14. Halaman menu kontak

11) Tampilan dashboard admin

Pada halaman dashboard admin dapat melihat semua transaksi. 
Website : $\underline{\text { http://pilar.unmermadiun.ac.id/index.php/pilarteknologi }}$

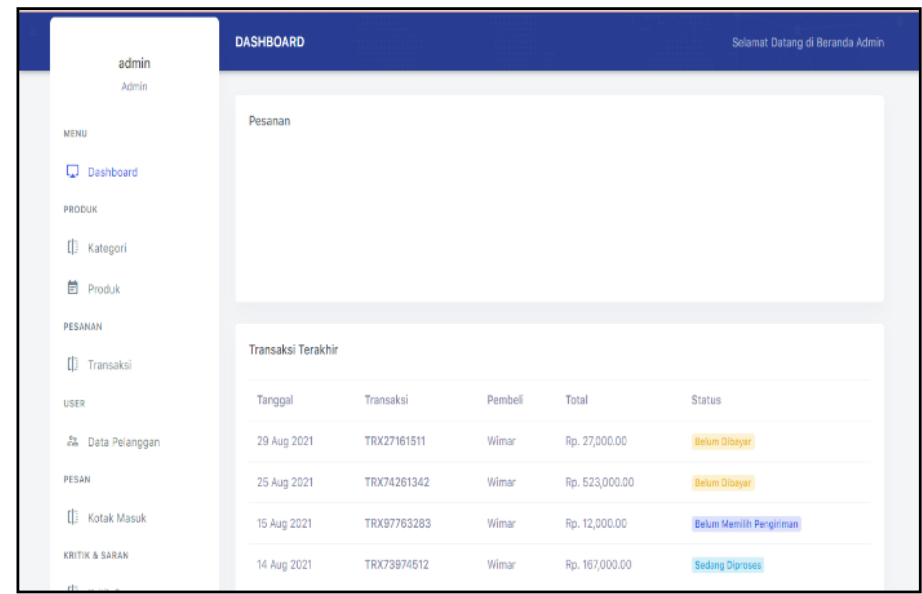

Gambar 15. Halaman dashboard admin

12) Tampilan Data kategori

Pada halaman data kategori admin dapat menambahkan kategori produk, mengedit, dan menghapus kategori produk.

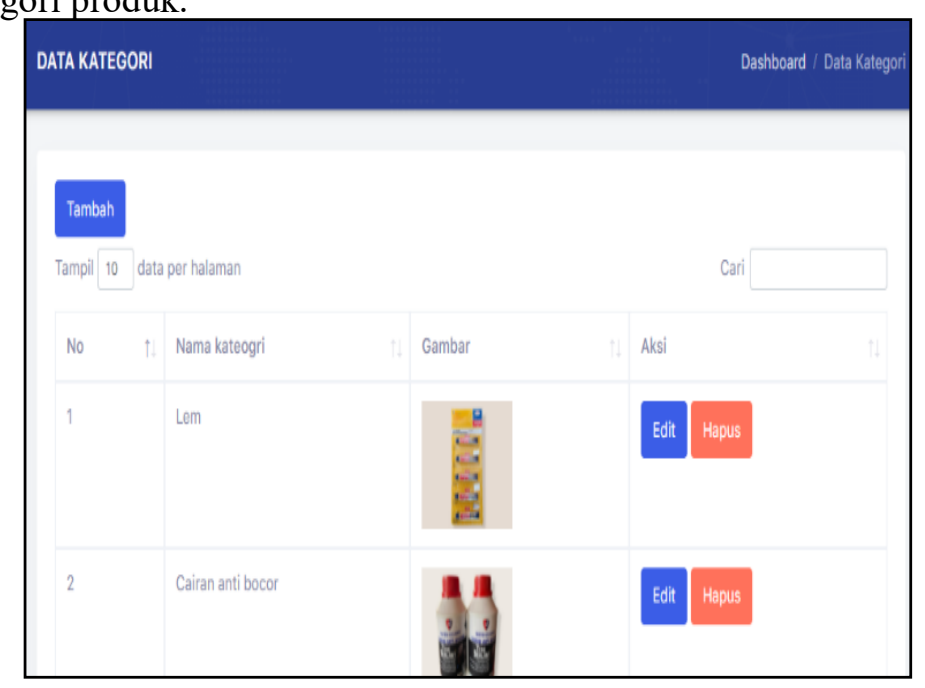

Gambar 16. Halaman data kategori

13) Tampilan Data produk

Pada halaman ini admin dapat menambahkan produk dengan mengisis kategori, nama produk, stok, harga, berat, diskon, dan deskripsi produk.

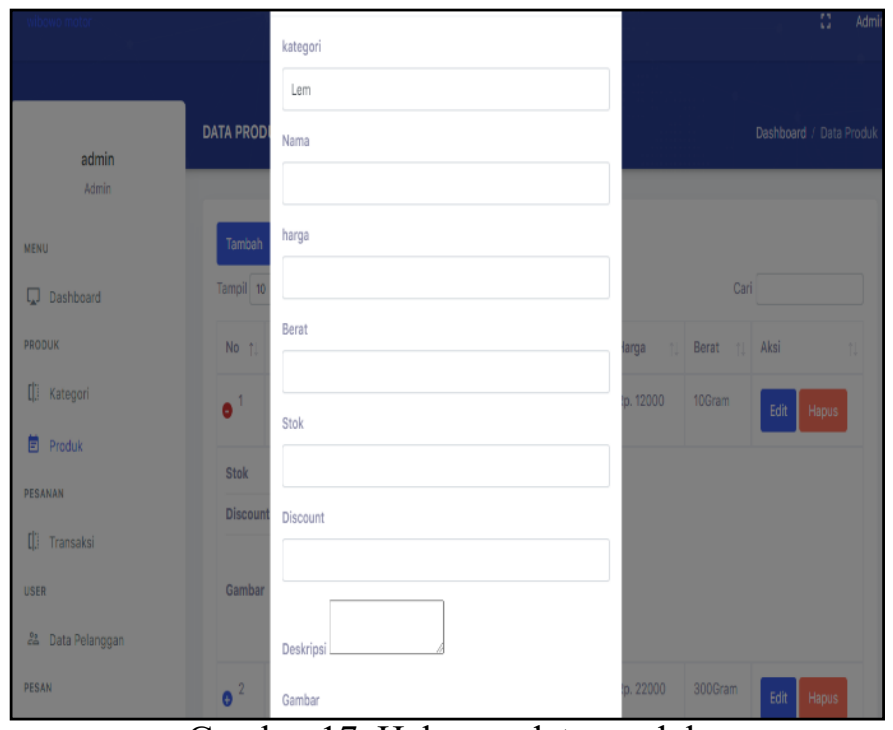

Gambar 17. Halaman data produk 
Website : http://pilar.unmermadiun.ac.id/index.php/pilarteknologi

14) Tampilan transaksi

Pada halaman transaksi admin dapat melihat upload pembaayaran pelanggan kemudian memferivikasi pembayaran pelanggan dengan mengubah status pembayaran.

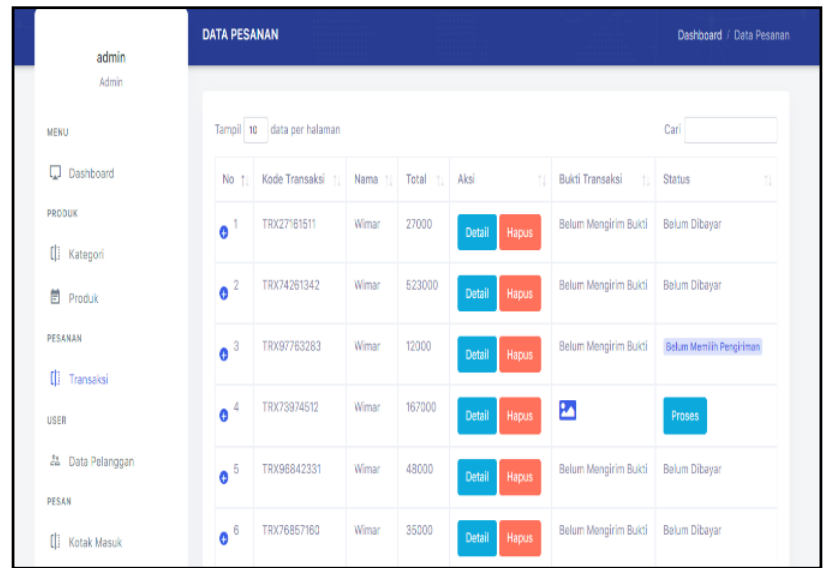

Gambar 18. Halaman transaksi

15) Tampilan data pelanggan

Pada halaman data pelanggan admin dapat melihat data pelanggan yang mendaftar dan admin dapar mengedit dan menghapus data pelanggan tersebut.

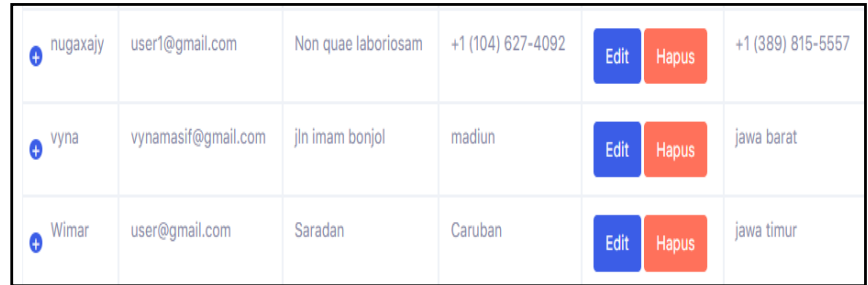

Gambar 19. Halaman data pelanggan

16) Tampilan kotak masuk

Pada halaman ini admin dapat melihat kotak masuk dari pelanggan mengenai produk.

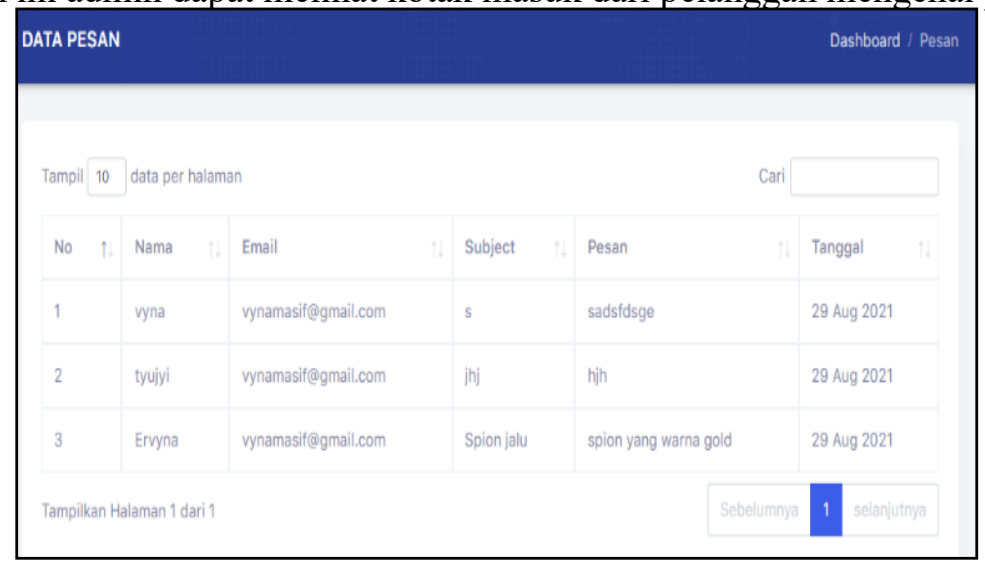

Gambar 20. Halaman kotak masuk

17) Tampilan kritik dan saran

Pada halaman ini admin dapat melihat kritik dan saran dari pelanggan. 


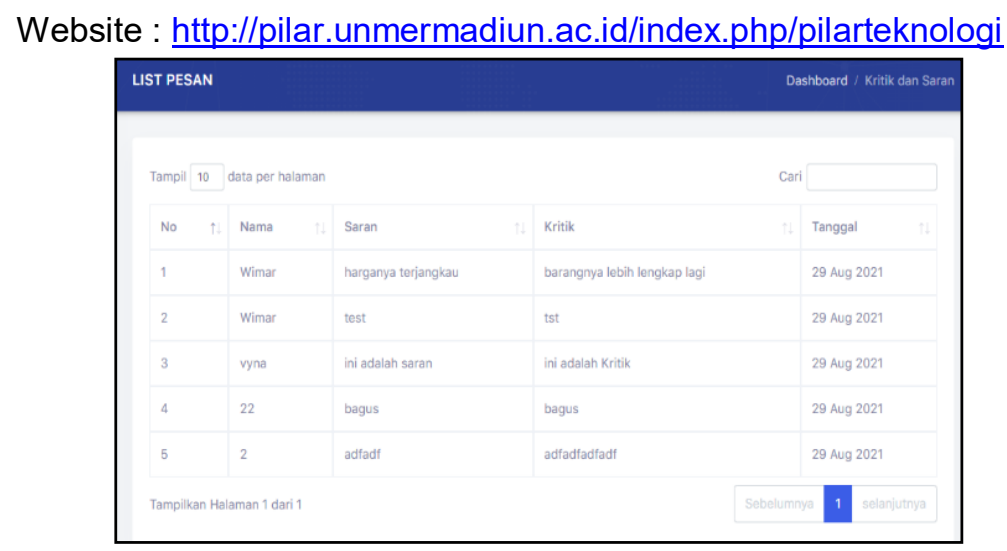

Gambar 21. Halaman kritik dan saran er

\section{KESIMPULAN}

Berdasarkan peneliian yang telah dilakukan dengan judul "Implementasi Customer Relationship Management Pada Sistem Informasi Pemasaran Toko Wibowo Motor", peneliti dapat menarik kesimpulan sebagai berikut:

1. Implementasi Customer Relationship Management pada sistem informasi pemasasaran ini dibangun untuk mempertahankan pelanggan dapat mempermudah toko untuk menarik pelanggan atau mempertahankan pelanggan agar tetap berbelanja di toko wibowo motor. Dalam strategi customer relationship management pada sistem informasi pemasaran ini ialah memberikan tampilan landing pages pada beranda dan gambar berupa informasi diskon dengan syarat dan ketentuan yang berlaku, memilih opsi pengambilan barang dengan memilih dua opsi yaitu ambil ditempat atau melalui jasa pengiriman, dan fitur pesan dan kritik saran kepada pihak toko. Dengan adanya sistem informasi pemasran toko wibowo motor dapat memperoleh data pelanggan secara lengkap agar dapat meningktkan jumlah pelanggan.

2. Telah dibangunnya Sistem Informasi Pemasaran berbasis website pada Toko Wibowo Motor akan membantu dalam proses bisnisnya. Salah satunya dengan memanfaatkan teknologi informasi.

\section{UCAPAN TERIMA KASIH}

Ucapan terimakasih penulis ucapkan kepada Ibu Hani Atun Mumtahana, S. Kom., M. Kom dan Bapak Ridho Pamungkas S.Kom, M. Kom selaku dosen pembimbing yang telah meluangkan waktunya untuk membimbing dan berbagi ilmu dan masukan yang telah diberikan. Rasa terima kasih penulis ucapkan kepada pemilik toko wibowo motor yang telah mendukung penelitian ini.

\section{DAFTAR PUSTAKA}

Amatullah, S., Delima, R., Syafitri, H., \& Ibrahim, A. (2018). Penerapan Strategi Customer Relationship Management (CRM) Pada Sistem Iinformasi Pelayanan Pelanggan Studi Kasus : Rumah Kreatif Ogan Ilir Indralay. Jurnal Teknologi Informasi Dan Ilmu Komputer (JTIIK), 5(2), 225-230. https://doi.org/10.25126/jtiik.201852555

Fitri Ayu and Nia Permatasari. (2018). perancangan sistem informasi pengolahan data PKL pada divisi humas PT pegadaian. Jurnal Infra Tech, 2(2), 12-26

http://journal.amikmahaputra.ac.id/index.php/JIT/article/download/3325

Hanafri, M. I., Iqbal, M., \& Prasetyo, A. B. (2019). Perancangan Aplikasi Interaktif Pembelajaran Pengenalan Komputer Dasar untuk Siswa Sekolah Dasar Berbasis Android. Jurnal Sisfotek Global, 9(1), 87-92.

http://journal.stmikglobal.ac.id/index.php/sisfotek/article/download/237/251

Masturi, H., Hasanawi, A., \& Hasanawi, A. (2021). Jurnal Inovasi Penelitian. Jurnal Inovasi Penelitian, l(10), 1-208.

Purnomo, W. A. (2020). Penerapan Model E-CRM (Costumer Relationship Management) Pada Perancangan Website. Jurnal SIMTIKA, 3(1), 13-18.

Putu, A. E. P. I. (Ed.). (2019). CUSTOMER RELATIONSHIP MANAGEMENT (CRM) Teori dan Praktek Berbasis Open Source.pdf. informatika bandung. 
Website : $\underline{\text { http://pilar.unmermadiun.ac.id/index.php/pilarteknologi }}$

Supandi, I., Yusuf, F., \& F, F. (2018). Implementasi Costumer Relationship Management (CRM) Pada Sistem Informasi Penjualan Ban Di Toko Lingga Ban Berbasis Web. Nuansa Informatika, 12(1), 20-28. https://doi.org/10.25134/nuansa.v12i1.1345

Hutahaean, J. (2015). Konsep Sistem Informasi. Deepublish. https://books.google.co.id/books?id=08LjCAAAQBAJ

Komputer, W. (2010). Panduan Belajar MySQL Database Server. Media Kita. https://books.google.co.id/books?id=rR1VNYpc08wC

Rahman, A. A., Supaidi, A., Aslamiah, I., \& Ibrahim, A. (2018). Implementasi Customer Relationship Management (Crm) Pelayanan Pelanggan (Corporate) Divisi Bges Pada Pt Telkom Witel Sumsel. JRMSI - Jurnal Riset Manajemen Sains Indonesia, 9(1), 72-78. https://doi.org/10.21009/jrmsi.009.1.05

Muslihudin, M., Pramesta, A., \& OFFSET, C. V. A. (n.d.). Analisis dan Perancangan Sistem Informasi Menggunakan Model Terstruktur dan UML. Penerbit Andi. https://books.google.co.id/books?id=2SU3DgAAQBAJ

Anggraeni, E. Y., Risanto, E., Basuki, Y., Nofianto, D., C, A. A., \& Offset, A. (n.d.). Pengantar Sistem Informasi. Penerbit Andi. https://books.google.co.id/books?id=8VNLDwAAQBAJ

Sumaryadi, A., \& Azzahra, I. S. S. (2014). Onlinekan!: Memulai Membangun Website Istimewa. Azzahra Publisher. https://books.google.co.id/books?id=UD8TBQAAQBAJ

Triyono, W. A. (2019). Manajemen Pemasaran. Deepublish. https://books.google.co.id/books?id=BmiDWAAQBAJ

Wahyuni, P., Nina, P., \& Lestari, E. (2020). Application of Web-Based Customer Relationship Management in Marketing Information System : PT . BPR Bali Dananiaga. 7(4), 43-47.

Zakaria, H., \& Marlia, A. E. (2019). Perancangan Sistem Informasi Customer Relationship Management ( CRM) untuk Meningkatkan Loyalitas dan Pelayanan Customers Berbasis Web dengan Model Waterfall. 2(2), 66-72. 